$$
\text { CONF-960982--3 }
$$

UCRL-JC-123067

\title{
High-Resolution Observations of Tungsten Liner Collapse and Early Jet Formation
}

K. A. Winer, R. D. Breithaupt, S. A. Muelder, D. W. Baum

\section{RECEIVED \\ AUIF 161996
OSTI}

This paper was prepared for submittal to the 16th International Symposium on BALLISTICS San Francisco, CA

September 23-28, 1996

\section{July 1996}
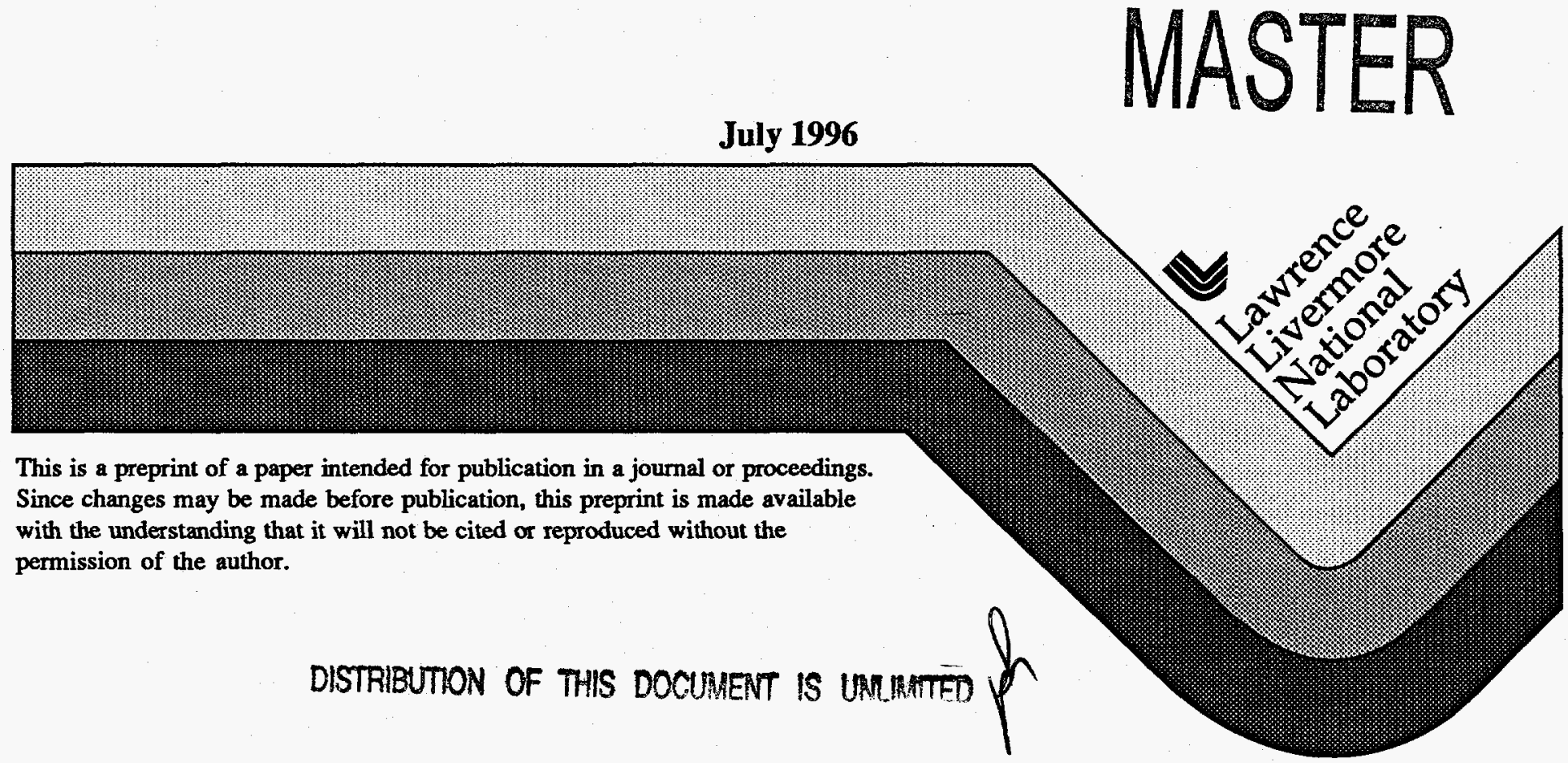


\section{DISCLAIMER}

This document was prepared as an account of work sponsored by an agency of the United States Government. Neither the United States Government nor the University of California nor any of their employees, makes any warranty, express or implied, or assumes any legal liability or responsibility for the accuracy, completeness, or usefulness of any information, apparatus, product, or process disclosed, or represents that its use would not infringe privately owned rights. Reference herein to any specific commercial product, process, or service by trade name, trademark, manufacturer, or otherwise, does not necessarily constitute or imply its endorsement, recommendation, or favoring by the United States Government or the University of California. The views and opinions of authors expressed herein do not necessarily state or reflect those of the Urited States Government or the University of California, and shall not be used for advertising or product endorsement purposes. 


\section{DISCLAIMER}

Portions of this document may be illegible in electronic image products. Images are produced from the best available original document. 
16TH INTERNATIONAL SYMPOSIUM ON BALLISTICS

SAN FRANCISCO, CA 23-28 SEPTEMBER, 1996

\title{
HIGH-RESOLUTION OBSERVATIONS OF TUNGSTEN LINER COLLAPSE AND EARLY JET FORMATION
}

Kris A. Winer, R. Don Breithaupt, Steve A. Muelder, and Dennis W. Baum

Lawrence Livermore National Laboratory, P.O. Box 808 L-170, Livermore, California 94551

\begin{abstract}
High-resolution photography of collapsing tungsten-lined shaped charges has revealed surface texturing both similar to and strikingly different from that previously observed during copper liner collapse. The behavior of three types of tungsten-lined shaped charges, with different liner designs and high explosives but with similar tungsten processing, were characterized by image-converter camera and fast-framing camera photography, and flash x-ray radiography. 120 mm-diameter, trumpet-shaped Octol charges produced surface blistering near the base of the tungsten liner, probably due to inhomogeneities near the linerexplosive interface resulting from cast loading. $148-\mathrm{mm}$-diameter, quasi-conical LX-14 charges produced smooth shocked-surface texture similar to that observed in conical, copper-lined LX-14 (Viper) charges. 81-mm-diameter, conical LX-20 charges produced severe radial texturing throughout the collapsing tungsten liner, which transitioned to azimuthal banding on the jet surface. For each type of charge, obscuring debris from the tungsten jet tip prevented clear imaging of the jet surface at late time.
\end{abstract}

\section{INTRODUCTION}

The high density of tungsten $(19.3 \mathrm{~g} / \mathrm{cc}$ ) makes it an ideal alternative to depleted uranium (a potential radiological hazard) for use in chemical-energy-driven, anti-armor munitions. However, unlike depleted uranium, tungsten jets undergo brittle fracture which has so far limited their utility for applications where maximizing jet elongation is important. This is due to the nature of tungsten, which is a high-strength, highly refractory metal. These properties make it difficult to melt cast tungsten. Various methods of tungsten processing have been pursued including chemical-vapor deposition to near-net shape and pressed-powder sintering followed by warm forging (the method used here). It has not yet been determined which processing techniques optimize tungsten jet elongation and, therefore, target penetration. Previous tungsten jet characterization experiments provide a wide variety of empirical data, but little progress has been made in developing a fundamental understanding of tungsten material failure processes. Lassila has suggested that tungsten is pulverized during shock loading, and that tungsten jet breakup behavior is related to high temperature embrittlement [1]. The problem is that a prerequisite to understanding material failure behavior is a knowledge of dynamic material properties such as density, temperature, stress, and impurity distributions, grain structure, and morphology, all of which have yet to be measured in collapsing liners and stretching jets. Through high-resolution photography with the image-converter camera, we have characterized dynamic tungsten material behavior by observing the evolution of liner and jet surface texture in response to shock loading. We have compared the results to similar observations made of copper liner collapse and early jet formation [2-5]. We have observed new behavior which validates some ideas about tungsten material failure processes and calls into question others. 


\section{SHAPED-CHARGE DESIGN}

The three different types of shaped charge characterized in this study are shown schematically in Fig. 1. Design details are given in Table 1.

Two 120-mm-diamater, tungsten-lined, aluminum-cased cast Octol (75\% HMX, 25\% TNT) charges were designed and assembled by Physics International. The machined inner and outer liner contours were specified by non-concentric circular arcs, resulting in a trumpet-shaped liner whose thickness varied between $\sim 0.6 \mathrm{~mm}$ at the hemispherical apex and $\sim 1.1 \mathrm{~mm}$ at the base. The charge was initiated with an RP-1 bridge-wire detonator, followed by a Reynolds precision initiation coupler (PIC) and a PBXN-5 booster abutting the Octol main charge.

Two 148-mm-diameter, tungsten-lined, machined LX-14 (95.5\% HMX, 4.5\% Estane) charges without cases were designed and assembled by Titan Corporation. The machined inner and outer tungsten liner contours were specified by 47 - and 58-coordinate-pair curves, respectively, resulting in a quasi-conical-shaped liner whose thickness varied between $\sim 0.7 \mathrm{~mm}$ at the hemispherical apex and $\sim 0.3 \mathrm{~mm}$ at the base. The charge was initiated with an RP-2 bridge-wire detonator with a 9-g precision PBXN-5 booster abutting an LX-14 disk. The disk was part of a tin/foam wave shaper assembly, which abutted the main LX-14 charge and provided enhanced energy transfer to the tungsten liner.

Two tungsten preforms and aluminum cases designed by ARDEC were supplied to LLNL. The liners were machined as simple 81 -mm-diameter cones, $0.384-\mathrm{mm}$-thick, with a $21^{\circ}$ halfangle. The cases were modified to accomodate loading with LLNL's experimental RX-08-HD (LX-20) paste explosive (74\% HMX, 20\% TMETN, 6\% urethane binder). The cured charge was initiated with an RP-2 bridge-wire detonator followed by a Reynolds PIC abutted to the main charge.

Table 1: Shaped-Charge Design Characteristics

\begin{tabular}{|l|c|c|}
\hline \multicolumn{1}{|c|}{ Design } & Tungsten Liner & \multicolumn{1}{c|}{ High-Explosive Charge } \\
\hline \hline Physics International & $1.4 \mathrm{~kg}$ trumpet & $120-\mathrm{mm}$ OD, 3.5 kg Cast Octol \\
\hline Titan Corporation & $1.1 \mathrm{~kg}$ quasi-cone & $148-\mathrm{mm}$ OD, $4.8 \mathrm{~kg}$ Machined LX-14 \\
\hline ARDEC & $0.26 \mathrm{~kg}$ simple cone & $81-\mathrm{mm}$ OD, $1.4 \mathrm{~kg}$ Cured Paste LX-20 \\
\hline
\end{tabular}

\section{TUNGSTEN PROCESSING}

The tungsten liner material for the $120-\mathrm{mm}$ - and 148-mm-diameter charges was isostatically pressed from $99.975 \mathrm{wt} \%$ pure tungsten powder by GTE Sylvania, and then warm forged into preforms in two stages by Northwest Industries. The tungsten liner material for the $81-\mathrm{mm}$ diameter charges was supplied by Schwarzkopf and warm (high-energy-rate) forged into preforms in two stages by EGG Oxnard, after which they were recrystallized in an inert atmosphere followed by a $20 \%$ final stage cold forging process [6]. Both surfaces of each tungsten liner were final-machined from the preforms, inspected, and assembled into munitions. The munitions were radiographed to assess uniformity of the high explosive prior to shipment to LLNL's Site 300 Experimental Testing Facility. 
Fig. 1 The three shaped-charge designs characterized in this study supplied by a) Physics International, b) Titan Corporation, and c) ARDEC. The liner and jet mass distributions at the indicated times are calculated using the CALE simulation code.
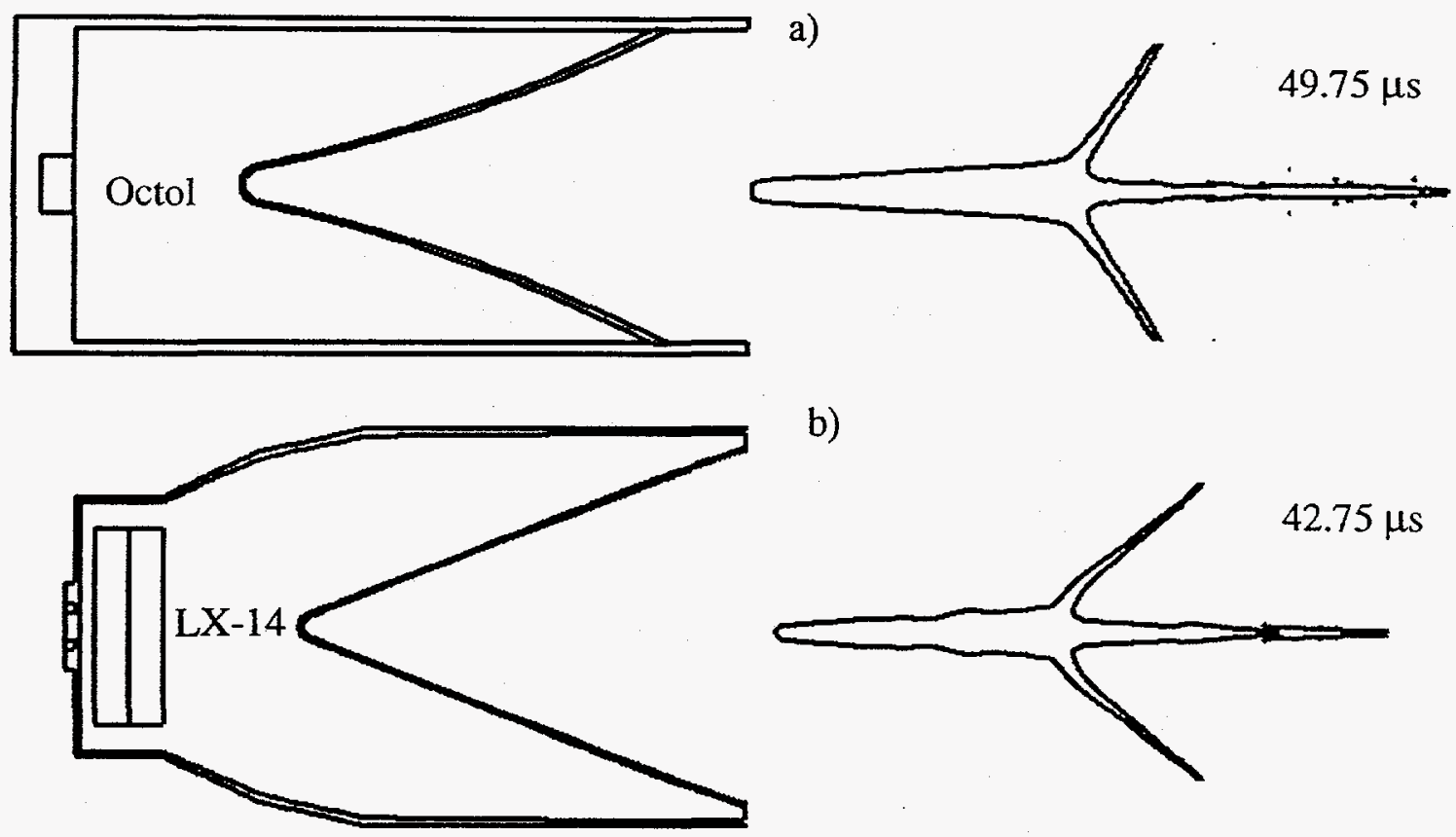

b)
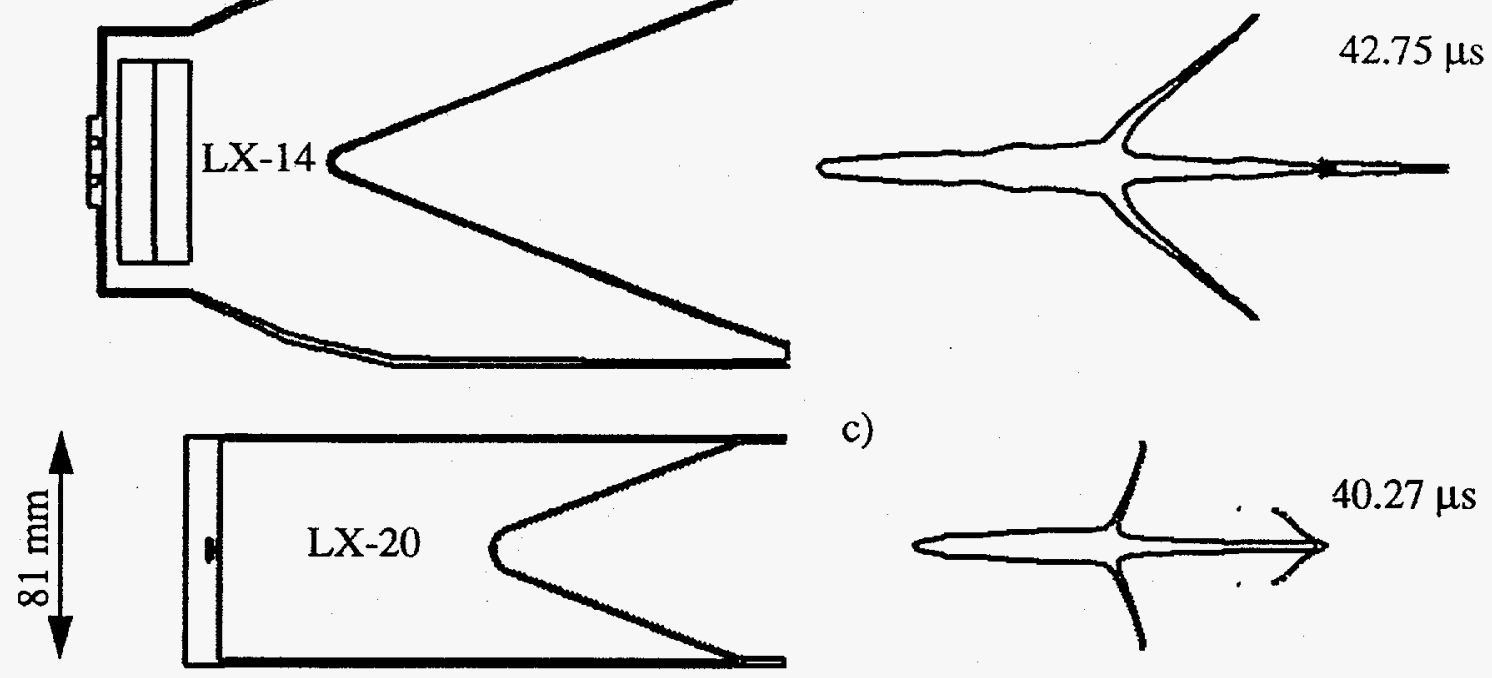

c)

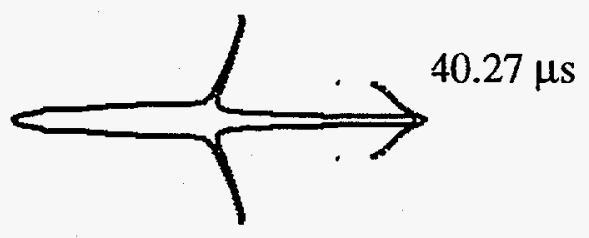

\section{SHAPED-CHARGE SIMULATION}

The shaped-charge performance was simulated using the two-dimensional LLNL-developed C-language-based Arbitrary-Lagrangian-Eulerian hydrocode CALE [7]. The simulation predicted stable jet development with tip speeds of $8.9,10.0$, and $8.1 \mathrm{~mm} / \mu \mathrm{s}$ for the Physics International, Titan, and ARDEC jets, respectively. The jet mass distributions calculated for the three jets are shown in Fig. 1. The simulated performance characteristics were used as the basis for the design of the experiments.

\section{EXPERIMENTAL DIAGNOSTICS}

The main experimental diagnostics consisted of optical records taken with two LLNLdesigned Cordin model 121 rotating-mirror framing cameras and eight LLNL-developed image-converter (IC) cameras. Pulsed $450-\mathrm{keV}$ radiography was also used to characterize the shaped-charge jets. The framing camera images were recorded on Kodak Ektachrome film with 200-ns frame exposure times. The records from the framing camera consisted of 26 frames separated by $\sim 1 \mu$ s intervals for a total record of $\sim 25 \mu \mathrm{s}$. High-explosive-driven argon candles were used to provide front-lit, broad-band illumination for color framing camera photography. The IC camera images were recorded on Kodak T-Max 3200 monochrome film with 20- or 35-ns exposure times. A Q-switched ruby laser system provided eight individual light 
pulses that were synchronized with the IC camera frames and passed through a ground-glass diffuser positioned near the experiment to provide illumination. In some cases, two simultaneous laser pulses were used for illumination to compensate for the low reflectivity of tungsten. A camera-mounted 1.5-nm band-pass filter centered at the 694.3-nm ruby laser wavelength was used to exclude extraneous light.

\section{EXPERIMENTAL DESIGN}

We carried out six experiments, two for each type of shaped charge, at LLNL's Site 300 between August 1994 and May 1996. In each case, four frames of the primary (IC camera) diagnostic were employed to capture liner collapse, and four frames were employed to capture jet necking and particulation. The setup of the jet particulation photography has been described elsewhere [8]. The results of the CALE simulations were used to choose optical views and frame times. Similarly, one of the two color rotating-mirror framing cameras was employed to follow liner collapse and one to follow jet particulation. Three pulsed-450-keV-x-ray radiographs were made of the stretching jet. These complementary diagnostics were intended to provide a complete record of tungsten jet necking and particulation. Instrumented 75-mmthick steel target arrays were placed 1-10 meters from the charges to measure jet penetration. In some cases, synchroballistic streak camera records of the stretching jet were also recorded.

\section{EXPERIMENTAL RESULTS-IC Camera}

The high spatial and temporal resolution of the image-converter camera are ideally suited to imaging shocked metal surfaces. Pulsed-laser illumination and electro-optic shuttering eliminate obscuring extraneous light and motion blur. This has allowed collapsing liner surfaces to be observed with spectacular clarity [2-5, 8]. However, high-explosive detonation products and jet debris can obscure surfaces to prevent clear observation even by the IC camera. This latter phenomenon prevented the clear observation of tungsten jet surfaces in most of these experiments. Obscuration was primarily caused by debris emanating from the tungsten jet tip, which began immediately upon jet formation and continued throughout the experiment. Images of jets from a copper-lined LX-14 charge (Viper) and a tungsten-lined Octol charge (Physics International) at $\sim 1$ charge diameter standoff are compared in Fig. 2 to illustrate this.

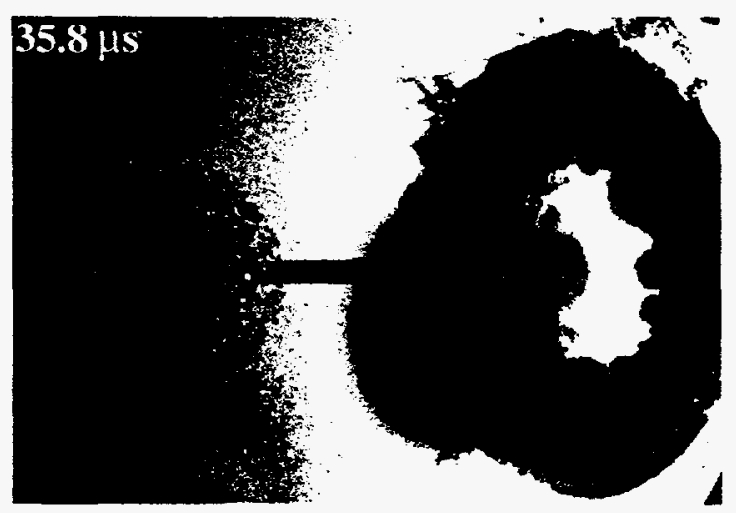

Fig. 2 Comparison of copper Viper jet (left) and tungsten Physics International jet (right) illustrating obscuring tungsten debris that prevented clear observation of tungsten jet surfaces in most cases.

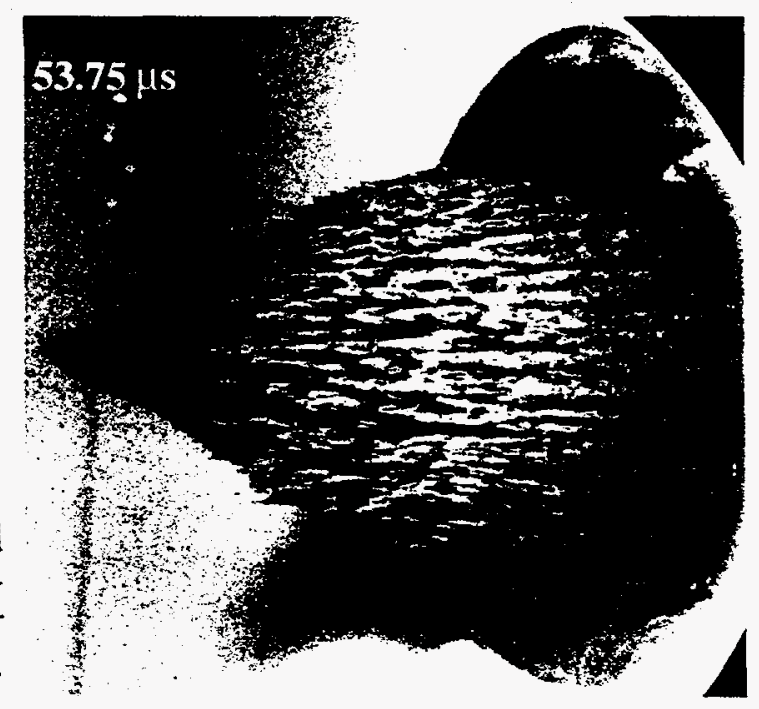


Because of this obscuring debris, we shall concentrate on the response of tungsten liner surfaces to shock loading. In some of the experiments, we place azimuthal gridlines on the liner surface with a flowball marker to allow the liner collapse to be more easily followed and quantified. Representative results of the IC camera photography are compiled in Figs. 3, 4, and 5.

Fig. 3 IC Camera Record of Tungsten-Lined Octol Charge (Physics International).

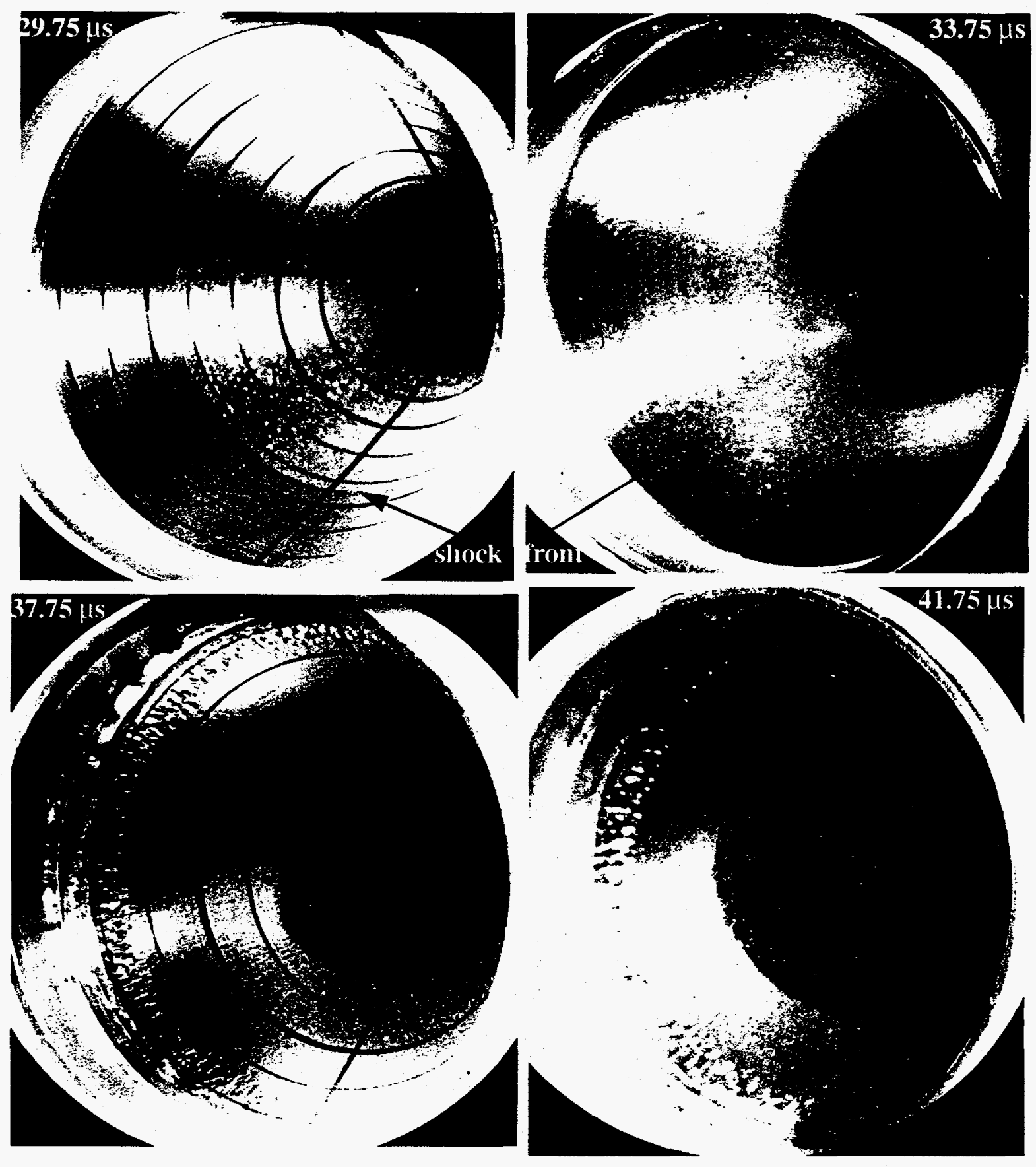

In the first experiments, two Physics International shaped charges were characterized (Fig. 3). The shock front at early times can be clearly seen. Behind the shock front, the tungsten initially appears smooth with localized variations in reflectivity. At $37.75 \mu$ s, a faint radial texture appears in the collapsing liner surface, which disappears behind the debris cloud emanating from the jet tip at later times. At the same time near the base of the tungsten liner a highly disturbed surface texture can be seen. The surface features there appear to result from many indi- 
vidual "blisters" rising up from the liner surface. This feature also eventually disappears behind the jet debris cloud. The jet tip speed was measured from $450-\mathrm{keV}$ radiography to be $9.0 \mathrm{~mm} / \mu \mathrm{s}$, which is close to the calculated $8.9 \mathrm{~mm} / \mu \mathrm{s}$. The "blistering" near the base of the liner has been observed before in copper-lined trumpet-shaped Octol charges and is likely due to inhomogeneities near the liner-explosive interface resulting from the cast loading process.

Fig. 4 IC Camera Record of Tungsten-Lined LX-14 Charge (Titan).
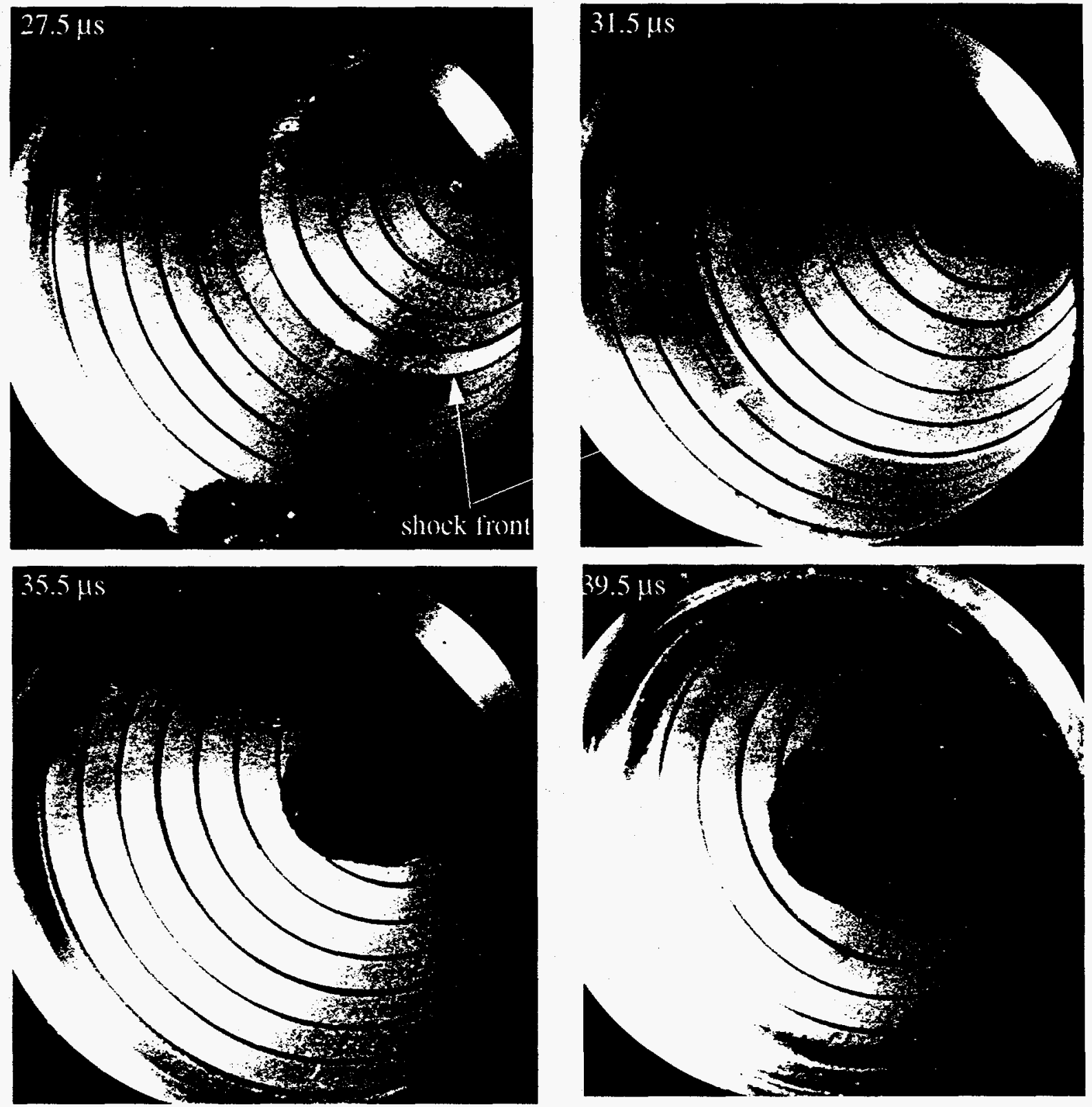

In the second experiments, two Titan shaped charges were characterized (Fig. 4). Again, the shock front can be clearly seen in the first two frames. There are very few localized variations in reflectivity, no evidence of radial texturing, and the liner surface behind the shock front appears smooth and uniform. The smooth liner surface texture persists throughout liner collapse. Again, heavy debris accompanies the jet, eventually obscuring the final stages of liner collapse. The jet tip speed was measured from $450-\mathrm{keV}$ radiography to be $9.6 \mathrm{~mm} / \mu \mathrm{s}$, which is close to the calculated $10.0 \mathrm{~mm} / \mu \mathrm{s}$. 
Fig. 5 IC Camera Record of Tungsten-Lined LX-20 Charge (ARDEC).
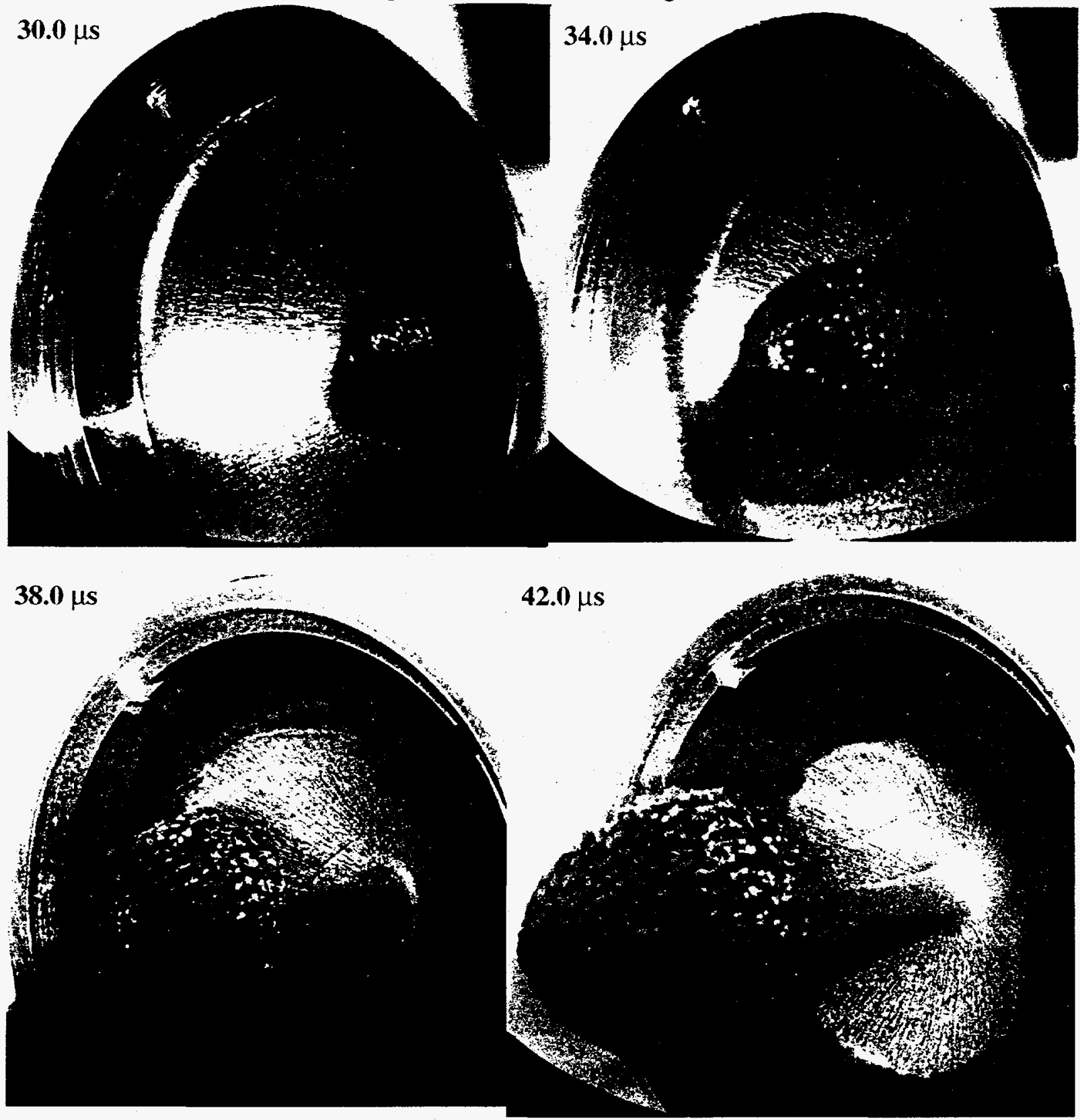

In the third experiments, two ARDEC shaped charges were characterized (Fig. 5). The shock front was not clearly observed in the early time images (16 and $20 \mu \mathrm{s})$ of the first experiment due to limitations placed on the depth of field by the radiographic requirements. In the second experiment, strong radial texturing of the tungsten liner surface can be clearly seen at each of the four frame times. The debris from the jet tip behaves more like that observed in copperlined Viper shaped charges (see Fig. 1.); it is limited to the near-jet-tip region. As a result, the tungsten jet surface can be clearly seen for the first time. The radial texturing of the liner is enhanced as collapse progresses, and there is a remarkable transition from radial texturing on the collapsing liner surface to azimuthal banding along the stretching jet surface. A shadow from the air bow shock can also be seen on the collapsing liner surface at $42 \mu$ s. The jet tip speed was measured from the $450-\mathrm{keV}$ radiographs to be $7.6 \mathrm{~mm} / \mu \mathrm{s}$, which is close to the calculated $8.1 \mathrm{~mm} / \mu \mathrm{s}$. The lower measured velocity might be a result of the poor characterization, and resulting inaccurate modelling, of the experimental paste explosive. 
EXPERIMENTAL RESULTS- Flash X-ray Radiography

In the table below we compare the particulation behavior quantified from the flash $\mathrm{x}$-ray radiographs for each type of charge.

Table 2: Comparison of Particulation Behavior

\begin{tabular}{|l|c|c|c|}
\hline \multicolumn{1}{|c|}{ Design } & Diameter $(\mathrm{mm})$ & Velocity Range $(\mathrm{mm} / \mu \mathrm{s})$ & Particulation Time $(\mu \mathrm{s})$ \\
\hline \hline Physics International & 120 & $4.8-9.0$ & $193.5+1-9.9$ \\
\hline Titan Corporation & 148 & $<9.6$ & $>155$ \\
\hline ARDEC & 81 & $3.9-7.6$ & $151.1+/-20.0$ \\
\hline
\end{tabular}

The Titan experiments were designed to measure optimum penetration so that the $450-\mathrm{keV}$ radiographs were taken before the particulation time of the jets. The particulation times for the other charges are the average time of separation of the first $\sim 20$ particles of the jet tip. In fact, a rather broad distribution of particulation times was measured in each case as indicated by the large standard deviations. Scaling the particulation time of the Physics International charge to the $81-\mathrm{mm}$-diameter of the ARDEC charge gives a relative particulation times of $130.6 \mu \mathrm{s}$, which is within one standard deviation of the $151.5 \mu$ s particulation time of the 81 -mm-diameter charge. Scaling the particulation time of the ARDEC charge up to $148-\mathrm{mm}$ diameter gives an estimated particulation time of $276 \mu \mathrm{s} ; 239 \mu \mathrm{s}$ if scaled up from the 120 -mm-diameter Physics International charge.

All of the jets exhibited rough particle surfaces with ductile necking regions between the particles. The 148-mm-diameter charge produced the jet that appeared to exhibit the most ductile behavior. The qualitative differences can be seen in Fig. 6 .

Fig. 6 Comparison of 450-keV Radiographs at Various Times.
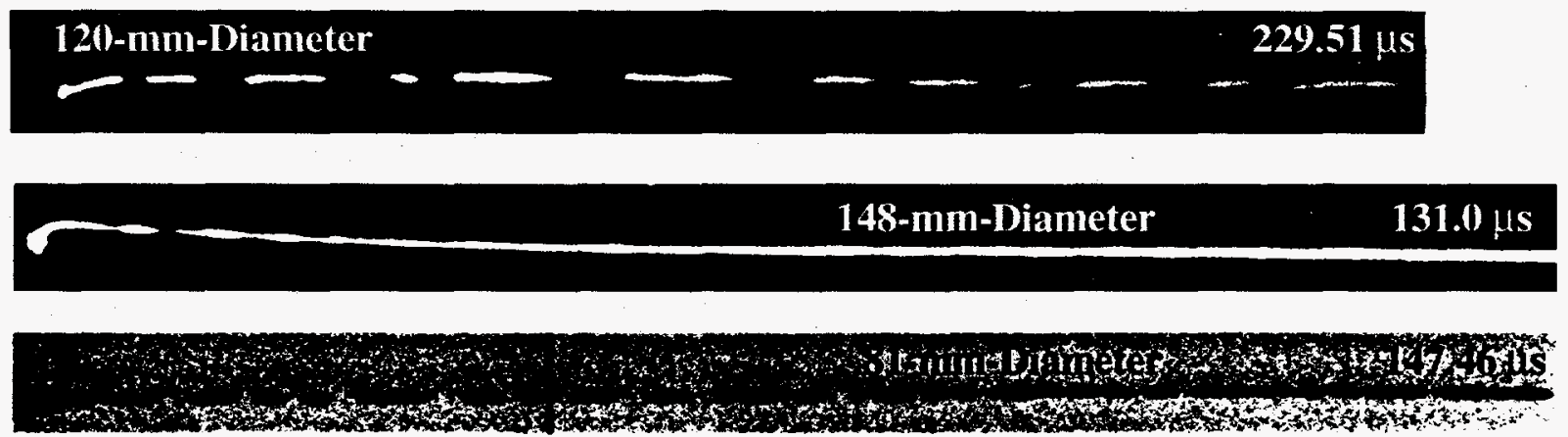

\section{DISCUSSION}

The appearance and evolution of surface texture during liner collapse is of more than academic interest. In a typical conical liner, the inner liner surface becomes the outer jet surface. Also, approximately $10 \%$ of the liner mass is tranformed into the jet, most of which comes from material less than 100 microns from the liner surface for the sub-millimeter-thick tungsten liners characterized here. This means that any deviation from smooth surface texture observed in high-resolution IC camera images could affect the jet particulation process. 
The blistering observed during liner collapse of the 120 -mm-diameter munitions is most pronounced near the base of the liner, which contributes to the slow tail of the jet. We did not include this part of the jet in our radiographic view since it does not contribute significantly to the overall penetration. While localized high reflectivity spots appeared behind the shock front everywhere on the liner, there is no obvious affect on the jet breakup behavior observed in the radiography. The smoothest surface texture was observed during collapse of the 148-mmdiameter liner, while the resulting jet appeared to display the most ductile necking and breakup behavior. The most textured surface was observed during collapse of the 81 -mm-diameter liner, while the resulting jet appeared rougher and the failure a bit more brittle.

It appears to us that the origin of the different surface texture observed during the function of the three different munitions must be related to the type of high explosive and the method of charge assembly. The fact that blistering has been observed in copper liners shock-loaded by cast-Octol charges supports this view. Also, recent color framing camera experiments on 81 mm-diameter copper cones driven by cured RX-08-HD paste explosive have shown severe radial surface texturing similar to that displayed in Fig. 5. The fact that cold-forged copper liners and warmed-forged tungsten liners display similar surface texturing appears to rule out any cause other than the type of high explosive and the method of charge assembly.

It is well known that gaps at the high explosive/liner interface can detrimentally affect liner collapse and perturb the resulting jet. It seems likely that any casting or paste loading process could be subject to problems at this interface including the presence of bubbles, density nonuniformities, poor adhesion, and high explosive constituent separation. The fact that the explosive charge appears uniform without interface gaps in post-assembly radiography does not guarantee that the high explosive/liner interface is defect free. The strong radial texturing observed in liners of munitions filled with RX-08-HD paste explosive and the weaker radial texturing observed in the liners of munitions filled with cast Octol suggests some type of radial asymmetry at the high explosive/liner interface as the cause.

This can easily be imagined to occur as the high explosive is loaded through an orifice at the back of the case and forced to flow around the cone apex up to the liner base. A quasi-radial flow pattern could leave a radial "non-uniformity" pattern at the high explosive/liner interface that might produce the observed collapsing-liner surface texture. We plan to investigate the high explosive filling process in detail in order to identify the origin of this behavior.

Finally, it seems clear to us that a model of tungsten failure dependent upon only one simple parameter is unlikely to account for the complex, widely varied behavior displayed in just these few tests. Tungsten can appear to fail ductily under some conditions and brittly under others, depending upon, among probably several things, the type of high explosive and method of explosive assembly. An adequate model would likely take into account material property distributions (grain structure, impurities, strain, machine texture, etc.) as well as shock history and processing details in addition to an accurate model of the hydrodynamic flow. Furthermore, tensile failure modelling in general requires an understanding of crack propagation, void formation and coalescence, etc., which is not yet fully mature.

It is probably optimistic to believe that tensile failure in any material can be fully understood until the phenomenon has been more completely characterized empirically than has so far been accomplished. We hope our results will provide some impetus to continue the effort. 


\section{ACKNOWLEDGMENTS}

We thank Don Oliver and John Burchfield at Physics International, Ron Brown and Scott Lewis at Titan Corporation, and Ernie Baker at ARDEC for supplying the charges used in this study and for many valuable technical discussions. We thank Lee Griffith for optimizing the $\mathrm{RX}-08-\mathrm{HD}$ filling process and for outstanding project engineering. We thank Denise Kuklo for superior engineering support, and Jack Lowry and the crew at Bunker 851, where the experiments were carried out, for their many essential contributions. Work performed under the auspices of the U.S. Department of Energy by Lawrence Livermore National Laboratory under contract \#W-7405-Eng-48. This work was supported in part by the Joint DoD/DOE Munitions Technology Development Program.

\section{REFERENCES}

[1] D. Lassila, "Mechanical Behavior of Tungsten Shaped Charge Liner Materials," Proc. 14th Int'l Ballistics Symposium, Quebec City, Canada, Sept. 26-29-1993.

[2] L.L. Shaw, S.A. Muelder, A.T. Rivera, J.L. Dunmire, and R.D. Breithaupt, "Electro-Optic Frame Photography with Pulsed Ruby Illumination," 20th International Congress on High Speed Photography and Photonics, Victoria, B.C., September 21-25, 1992.

[3] D.W. Baum, L.L. Shaw, and C.A. Honodel, "Application of High-Resolution Optical Technique to Shaped-Charge Jet Formation," Proc. 13th Int' l Ballistics Symposium, Stockholm, Sweden, May 1992.

[4] D. Baum, L. Shaw, S.C. Simonson, and K. Winer, "Liner Collapse and Early Jet Formation in a Shaped Charge," Proc. 14th Int'l Ballistics Symposium, Quebec City, Canada, Sept. 26-29 1993.

[5] K. Winer, L. Shaw, S. Muelder, D. Breithaupt, and D. Baum, "Dynamic Behavior of a Shear-Formed Shaped-Charge Liner," Propellants, Explosives, and Pyrotechnics 18 (1993) 345-351.

[6] E. Baker, private communication.

[7] R. Tipton, private communication.

[8] K. Winer, D. Breithaupt, L. Shaw, S. Muelder, and D. Baum, "High-Speed, High-Resolution Observations of Shaped-Charge Jets Undergoing Particulation,'Proc. 15th Int'l Ballistics Symposium, Jerusalem, Israel, May 21-24, 1995. 